\title{
STRONG CONVERGENCE OF COMPOSITE ITERATIVE METHODS FOR NONEXPANSIVE MAPPINGS
}

\author{
Jong SoO Jung
}

\begin{abstract}
Let $E$ be a reflexive Banach space with a weakly sequentially continuous duality mapping, $C$ be a nonempty closed convex subset of $E, f: C \rightarrow C$ a contractive mapping (or a weakly contractive mapping), and $T: C \rightarrow C$ a nonexpansive mapping with the fixed point set $F(T) \neq$ $\emptyset$. Let $\left\{x_{n}\right\}$ be generated by a new composite iterative scheme: $y_{n}=$ $\lambda_{n} f\left(x_{n}\right)+\left(1-\lambda_{n}\right) T x_{n}, x_{n+1}=\left(1-\beta_{n}\right) y_{n}+\beta_{n} T y_{n},(n \geq 0)$. It is proved that $\left\{x_{n}\right\}$ converges strongly to a point in $F(T)$, which is a solution of certain variational inequality provided the sequence $\left\{\lambda_{n}\right\} \subset(0,1)$ satisfies $\lim _{n \rightarrow \infty} \lambda_{n}=0$ and $\sum_{n=0}^{\infty} \lambda_{n}=\infty,\left\{\beta_{n}\right\} \subset[0, a)$ for some $0<a<1$ and the sequence $\left\{x_{n}\right\}$ is asymptotically regular.
\end{abstract}

\section{Introduction}

Let $E$ be a real Banach space and $C$ be a nonempty closed convex subset of $E$. Recall that a mapping $f: C \rightarrow C$ is a contraction on $C$ if there exists a constant $k \in(0,1)$ such that $\|f(x)-f(y)\| \leq k\|x-y\|, x, y \in C$. We use $\Sigma_{C}$ to denote the collection of all contractions on $C$. That is, $\Sigma_{C}=$ $\{f: C \rightarrow C \mid f$ is a contraction with constant $k\}$. Let $T: C \rightarrow C$ be a nonexpansive mapping (recall that a mapping $T: C \rightarrow C$ is nonexpansive if $\|T x-T y\| \leq\|x-y\|, x, y \in C)$ and $F(T)$ denote the set of fixed points of $T$; that is, $F(T)=\{x \in C: x=T x\}$.

We consider the iterative scheme: for a nonexpansive mapping $T, f \in \Sigma_{C}$ and $\lambda_{n} \in(0,1)$,

$$
x_{n+1}=\lambda_{n} f\left(x_{n}\right)+\left(1-\lambda_{n}\right) T x_{n}, \quad n \geq 0 .
$$

As a special case of (1.1), the following iterative scheme

$$
z_{n+1}=\lambda_{n} u+\left(1-\lambda_{n}\right) T z_{n}, \quad n \geq 0,
$$

Received January 15, 2008

2000 Mathematics Subject Classification. 47H09, 47H10, 47J20, 47J25, 49M05.

Key words and phrases. viscosity approximation method, nonexpansive mapping, composite iterative scheme, contractive mapping, weakly contractive mapping, weakly sequentially continuous duality mapping, variational inequality.

This study was supported by research funds from Dong-A University. 
where $u, z_{0} \in C$ are arbitrary (but fixed), has been investigated by many authors: see, for example, Cho et al. [3], Halpern [6], Jung [7], Lions [12], Reich [17, 18], Shioji and Takahashi [19], Wittmann [20] and Xu [21]. The authors above showed that the sequence $\left\{z_{n}\right\}$ generated by (1.2) converges strongly to a point in the fixed point set $F(T)$ under appropriate conditions on $\left\{\lambda_{n}\right\}$ in either Hilbert spaces or certain Banach spaces.

The viscosity approximation method of selecting a particular fixed point of a given nonexpansive mapping was proposed by Moudafi [14]. In 2004, Xu [22] extended Theorem 2.2 of Moudafi [14] for the iterative scheme (1.1) to a Banach space setting using the followings conditions on $\left\{\lambda_{n}\right\}$ :

(H1) $\lim _{n \rightarrow \infty} \lambda_{n}=0 ; \sum_{n=0}^{\infty} \lambda_{n}=\infty$ or equivalently, $\prod_{n=0}^{\infty}\left(1-\lambda_{n}\right)=0$;

(H2) $\sum_{n=0}^{\infty}\left|\lambda_{n+1}-\lambda_{n}\right|<\infty$ or $\lim _{n \rightarrow \infty} \frac{\lambda_{n}}{\lambda_{n+1}}=1$.

Recently, Kim and $\mathrm{Xu}$ [11] provided a simpler modification of Mann iterative scheme (1.3) in a uniformly smooth Banach space as follows:

$$
\left\{\begin{array}{l}
x_{0}=x \in C, \\
y_{n}=\beta_{n} x_{n}+\left(1-\beta_{n}\right) T x_{n}, \\
x_{n+1}=\alpha_{n} u+\left(1-\alpha_{n}\right) y_{n},
\end{array}\right.
$$

where $u \in C$ is an arbitrary (but fixed) element, and $\left\{\alpha_{n}\right\}$ and $\left\{\beta_{n}\right\}$ are two sequences in $(0,1)$. They proved that $\left\{x_{n}\right\}$ generated by $(1.3)$ converges to a fixed point of $T$ under the control conditions:

(i) $\lim _{n \rightarrow \infty} \alpha_{n}=0, \quad \lim _{n \rightarrow \infty} \beta_{n}=0$;

(ii) $\sum_{n=0}^{\infty} \alpha_{n}=\infty, \quad \sum_{n=0}^{\infty} \beta_{n}=\infty$;

(iii) $\sum_{n=0}^{\infty}\left|\alpha_{n+1}-\alpha_{n}\right|<\infty, \quad \sum_{n=0}^{\infty}\left|\beta_{n+1}-\beta_{n}\right|<\infty$.

In this paper, motivated by above-mentioned results, as the viscosity approximation method, we consider a new composite iterative scheme for a nonexpansive mapping $T$ :

$$
\left\{\begin{array}{l}
x_{0}=x \in C \\
y_{n}=\lambda_{n} f\left(x_{n}\right)+\left(1-\lambda_{n}\right) T x_{n} \\
x_{n+1}=\left(1-\beta_{n}\right) y_{n}+\beta_{n} T y_{n}
\end{array}\right.
$$

where $\left\{\lambda_{n}\right\},\left\{\beta_{n}\right\} \subset(0,1)$. First, we prove the strong convergence of the sequence $\left\{x_{n}\right\}$ generated by (IS) under the suitable conditions on the control parameters $\left\{\lambda_{n}\right\}$ and $\left\{\beta_{n}\right\}$ and the asymptotic regularity on $\left\{x_{n}\right\}$ in a reflexive Banach space with a weakly sequentially continuous duality mapping. Moreover, we show that the strong limit is a solution of certain variational inequality. Next we study the viscosity approximation with the weakly contractive mapping to a fixed point of a nonexpansive mapping in the same Banach space. The main results improve and complement the corresponding results of $[3,6,12,14,17,18,19,20,21,22]$. In particular, if $\beta_{n}=0$ for all $n \geq 0$, then 
(IS) reduces to (1.1). We point out that the iterative scheme (IS) is a new method for finding a fixed point of $T$.

\section{Preliminaries and lemmas}

Let $E$ be a real Banach space with norm $\|\cdot\|$ and let $E^{*}$ be its dual. The value of $f \in E^{*}$ at $x \in E$ will be denoted by $\langle x, f\rangle$. When $\left\{x_{n}\right\}$ is a sequence in $E$, then $x_{n} \rightarrow x$ (resp., $x_{n} \rightarrow x$ ) will denote strong (resp., weak) convergence of the sequence $\left\{x_{n}\right\}$ to $x$.

The norm of $E$ is said to be Gâteaux differentiable (and $E$ is said to be smooth) if

$$
\lim _{t \rightarrow 0} \frac{\|x+t y\|-\|x\|}{t}
$$

exists for each $x, y$ in its unit sphere $U=\{x \in E:\|x\|=1\}$.

By a gauge function we mean a continuous strictly increasing function $\varphi$ defined on $\mathbb{R}^{+}:=[0, \infty)$ such that $\varphi(0)=0$ and $\lim _{r \rightarrow \infty} \varphi(r)=\infty$. The mapping $J_{\varphi}: E \rightarrow 2^{E^{*}}$ defined by

$$
J_{\varphi}(x)=\left\{f \in E^{*}:\langle x, f\rangle=\|x\|\|f\|,\|f\|=\varphi(\|x\|)\right\} \text { for all } x \in E
$$

is called the duality mapping with gauge function $\varphi$. In particular, the duality mapping with gauge function $\varphi(t)=t$ denoted by $J$, is referred to as the normalized duality mapping. It is known (cf. [4]) that a Banach space $E$ is smooth if and only if the normalized duality mapping $J$ is single-valued.

We say that a Banach space $E$ has a weakly sequential continuous duality mapping if there exists a gauge function $\varphi$ such that the duality mapping $J_{\varphi}$ is single-valued and continuous from the weak topology to the weak* topology, that is, for any $\left\{x_{n}\right\} \in E$ with $x_{n} \rightarrow x, J_{\varphi}\left(x_{n}\right) \stackrel{*}{\rightarrow} J_{\varphi}(x)$. For example, every $l^{p}$ space $(1<p<\infty)$ has a weakly sequentially continuous duality mapping with gauge function $\varphi(t)=t^{p-1}$.

Let $D$ be a subset of $C$. Then a mapping $Q: C \rightarrow D$ is said to be a retraction from $C$ onto $D$ if $Q x=x$ for all $x \in D$. A retraction $Q: C \rightarrow D$ is said to be sunny if $Q(Q x+t(x-Q x))=Q x$ for all $x \in C$ and $t \geq 0$ with $Q x+t(x-Q x) \in C$. A subset $D$ of $C$ is said to be a sunny nonexpansive retract of $C$ if there exists a sunny nonexpansive retraction of $C$ onto $D$. In a smooth Banach space $E$, it is well-known [5, p. 48] that $Q$ is a sunny nonexpansive retraction from $C$ onto $D$ if and only if the following condition holds:

$$
\langle x-Q x, J(z-Q x)\rangle \leq 0, \quad x \in C, \quad z \in D .
$$

We need the following lemmas for the proof of our main results. (Lemma 2.1 was also given in Jung and Morales [9] and Lemma 2.2 is essentially Lemma 2 of Liu [13] (also see [21])).

Lemma 2.1. Let $E$ be a real Banach space and $J$ be the duality mapping. Then, for any given $x, y \in E$, one has

$$
\|x+y\|^{2} \leq\|x\|^{2}+2\langle y, j(x+y)\rangle
$$


for all $j(x+y) \in J(x+y)$.

Lemma 2.2. Let $\left\{s_{n}\right\}$ be a sequence of non-negative real numbers satisfying

$$
s_{n+1} \leq\left(1-\alpha_{n}\right) s_{n}+\alpha_{n} \gamma_{n}+\delta_{n}, \quad n \geq 0
$$

where $\left\{\alpha_{n}\right\},\left\{\gamma_{n}\right\}$ and $\left\{\delta_{n}\right\}$ satisfy the following conditions:

(i) $\left\{\alpha_{n}\right\} \subset[0,1]$ and $\sum_{n=0}^{\infty} \alpha_{n}=\infty$,

(ii) $\lim \sup _{n \rightarrow \infty} \gamma_{n} \leq 0$ or $\sum_{n=1}^{\infty} \alpha_{n} \gamma_{n}<\infty$,

(iii) $\delta_{n} \geq 0(n \geq 0), \sum_{n=0}^{\infty} \delta_{n}<\infty$.

Then $\lim _{n \rightarrow \infty} s_{n}=0$.

Let $\mu$ be a continuous linear functional on $l^{\infty}$ and $\left(a_{0}, a_{1}, \ldots\right) \in l^{\infty}$. We write $u_{n}\left(a_{n}\right)$ instead of $\mu\left(\left(a_{0}, a_{1}, \ldots\right)\right) . \mu$ is said to be Banach limit if $\mu$ satisfies $\|\mu\|=\mu(1)=1$ and $u_{n}\left(a_{n+1}\right)=\mu_{n}\left(a_{n}\right)$ for all $\left(a_{0}, a_{1}, \ldots\right) \in l^{\infty}$. If $\mu$ is a Banach limit, the following are well-known:

(i) for all $n \geq 1, a_{n} \leq c_{n}$ implies $\mu\left(a_{n}\right) \leq \mu\left(c_{n}\right)$,

(ii) $\mu\left(a_{n+1}\right)=\mu\left(a_{n}\right)$,

(iii) $\liminf \operatorname{in}_{n \rightarrow \infty} a_{n} \leq \mu_{n}\left(a_{n}\right) \leq \lim \sup _{n \rightarrow \infty} a_{n}$ for all $\left(a_{0}, a_{1}, \ldots\right) \in l^{\infty}$.

The following lemma was given in [19].

Lemma 2.3. Let $a \in \mathbb{R}$ be a real number and let a sequence $\left\{a_{n}\right\} \in l^{\infty}$ satisfy $\mu_{n}\left(a_{n}\right) \leq a$ for all Banach limit $\mu$. If $\lim \sup _{n \rightarrow \infty}\left(a_{n+1}-a_{n}\right) \leq 0$, then $\lim \sup _{n \rightarrow \infty} a_{n} \leq a$.

Recall a mapping $A: C \rightarrow C$ is said to be weakly contractive if

$$
\|A x-A y\| \leq\|x-y\|-\psi(\|x-y\|) \quad \text { for all } x, y \in K,
$$

where $\psi:[0,+\infty) \rightarrow[0,+\infty)$ is a continuous and strictly increasing function such that $\psi$ is positive on $(0, \infty)$ and $\psi(0)=0$. Obviously, the class of the weakly contractive mappings contains the class of the contractive mappings as a special case $(\psi(t)=(1-k) t)$. Rhodes [16] obtained the following result for weakly contractive mapping.

Lemma 2.4 ([16, Theorem 2]). Let $(X, d)$ be a complete metric space, and $A$ a weakly contractive mapping on $X$. Then $A$ has a unique fixed point $p$ in $X$. Moreover, for $x \in X,\left\{A^{n} x\right\}$ converges strongly to $p$.

The following lemma was given in $[1,2]$.

Lemma 2.5. Let $\left\{s_{n}\right\}$ and $\left\{\gamma_{n}\right\}$ be two sequences of nonnegative real numbers and $\left\{\lambda_{n}\right\}$ a sequence of positive numbers satisfying the conditions

(i) $\sum_{n=0}^{\infty} \lambda_{n}=\infty$ or, equivalently, $\prod_{n=0}^{\infty}\left(1-\lambda_{n}\right)=0$,

(ii) $\lim _{n \rightarrow \infty} \frac{\gamma_{n}}{\lambda_{n}}=0$.

Let the recursive inequality

$$
s_{n+1} \leq s_{n}-\lambda_{n} \psi\left(s_{n}\right)+\gamma_{n}, \quad n=0,1,2, \ldots,
$$

be given where $\psi(t)$ is a continuous and strict increasing function on $[0,+\infty)$ with $\psi(0)=0$. Then $\lim _{n \rightarrow \infty} s_{n}=0$. 
Finally, the sequence $\left\{x_{n}\right\}$ in $E$ is said to be asymptotically regular if

$$
\lim _{n \rightarrow \infty}\left\|x_{n+1}-x_{n}\right\|=0 \text {, that is, } x_{n+1}-x_{n} \rightarrow 0 \text {. }
$$

\section{Main results}

First, using the asymptotic regularity, we study a strong convergence theorem for a composite iterative method for the nonexpansive mapping with the contractive mapping.

For abbreviation, we set the duality mapping $J:=J_{\varphi}$. In all our proofs we assume, without loss of generality, that $J$ is normalized.

Let $T: C \rightarrow C$ be a nonexpansive mapping. Then, for any $t \in(0,1)$ and $f \in \Sigma_{C}, t f+(1-t) T: C \rightarrow C$ defines a contraction. Thus, by the Banach contraction principle, there exists a unique fixed point $x_{t}^{f}$ satisfying

$$
x_{t}^{f}=t f\left(x_{t}^{f}\right)+(1-t) T x_{t}^{f} .
$$

For simplicity we will write $x_{t}$ for $x_{t}^{f}$ provided no confusion occurs.

The following result was given by Jung [8] (see also O'Hara et al. [15] and $\mathrm{Xu}[23]$ for the case that $f(x)=u$ a constant). We refer Jung and Sahu [10] for the case of non-LIpschizian mappings.

Theorem J ([8]). Let $E$ be a reflexive Banach space with a weakly sequentially continuous duality mapping $J$. Let $C$ be a nonempty closed convex subset of $E$ and $T$ nonexpansive mappings from $C$ into itself with $F(T) \neq \emptyset$. Then $\left\{x_{t}\right\}$ defined by $(\mathrm{R})$ converges strongly to a point in $F(T)$. If we define $Q: \Sigma_{C} \rightarrow$ $F(T)$ by

$$
Q(f):=\lim _{t \rightarrow 0^{+}} x_{t}, \quad f \in \Sigma_{C},
$$

then $Q(f)$ solves a variational inequality

$$
\langle(I-f)(Q(f)), J(Q(f)-p)\rangle \leq 0, \quad f \in \Sigma_{C}, \quad p \in F(T) .
$$

Remark 3.1. In Theorem J, if $f(x)=u \in C$ is a constant, then (3.1) become

$$
\langle Q u-u, J(Q u-p)\rangle \leq 0, \quad u \in C, \quad p \in F(T) .
$$

Hence by (2.1), $Q$ reduces to the sunny nonexpansive retraction from $C$ to $F(T)$. Namely $F(T)$ is a sunny nonexpansive retraction of $C$.

Using Theorem J, we have the following result.

Proposition 3.1. Let $E$ be a reflexive Banach space having a weakly sequentially continuous duality mapping $J$. Let $C$ be a nonempty closed convex subset of $E$ and $T$ nonexpansive mappings from $C$ into itself with $F(T) \neq \emptyset$. Let $f \in \Sigma_{C}$ and and $\mu$ a Banach limit. Let $\left\{y_{n}\right\}$ be a bounded sequence in $C$. If $\lim _{n \rightarrow \infty}\left\|y_{n}-T y_{n}\right\|=0$, then

$$
\mu_{n}\left\langle(I-f)(Q(f)), J\left(Q(f)-y_{n}\right)\right\rangle \leq 0,
$$

where $Q: \Sigma_{C} \rightarrow F$ is defined by $Q(f)=\lim _{t \rightarrow 0^{+}} x_{t}$ and $x_{t}$ is defined by $(\mathrm{R})$. 
Proof. Note that the definition of the weak continuity of duality mapping $J$ implies that $E$ is smooth. By Theorem J, there exists $\lim _{t \rightarrow 0^{+}} x_{t}=Q(f)$, where $x_{t}$ is defined by $(\mathrm{R})$.

First, we show that $\left\|x_{t}-z\right\| \leq \frac{1}{1-k}\|f(z)-z\|$ for $t \in(0,1)$ and $z \in F(T)$ and so $\left\{x_{t}\right\},\left\{T x_{t}\right\}$ and $\left\{f\left(x_{t}\right)\right\}$ are bounded. To this end, let $z \in F(T)$ and $t \in(0,1)$. Then

$$
x_{t}-z=t\left(f\left(x_{t}\right)-z\right)+(1-t)\left(T x_{t}-T z\right)
$$

and so

$$
\begin{aligned}
\left\|x_{t}-z\right\| & \leq t\left\|f\left(x_{t}\right)-z\right\|+(1-t)\left\|T x_{t}-T z\right\| \\
& \leq t\left\|f\left(x_{t}\right)-z\right\|+(1-t)\left\|x_{t}-z\right\| .
\end{aligned}
$$

This gives that

$$
\begin{aligned}
\left\|x_{t}-z\right\| & \leq\left\|f\left(x_{t}\right)-z\right\| \leq\left\|f\left(x_{t}\right)-f(z)\right\|+\|f(z)-z\| \\
& \leq k\left\|x_{t}-z\right\|+\|f(z)-z\|
\end{aligned}
$$

and so

$$
\left\|x_{t}-z\right\| \leq \frac{1}{1-k}\|f(z)-z\| .
$$

Hence $\left\{x_{t}\right\}$ is bounded, so are $\left\{f\left(x_{t}\right)\right\}$ and $\left\{T x_{t}\right\}$.

Now we can write

$$
x_{t}-y_{n}=(1-t)\left(T x_{t}-y_{n}\right)+t\left(f\left(x_{t}\right)-y_{n}\right) .
$$

Applying Lemma 2.1, we have

$$
\left\|x_{t}-y_{n}\right\|^{2} \leq(1-t)^{2}\left\|T x_{t}-y_{n}\right\|^{2}+2 t\left\langle f\left(x_{t}\right)-y_{n}, J\left(x_{t}-y_{n}\right)\right\rangle .
$$

Using $\lim _{n \rightarrow \infty}\left\|y_{n}-T y_{n}\right\|=0$, we derive

$$
\left\|T x_{t}-y_{n}\right\| \leq\left\|x_{t}-y_{n}\right\|+e_{n},
$$

where $e_{n}=\left\|y_{n}-T y_{n}\right\| \rightarrow 0$ as $n \rightarrow \infty$, and

$$
\left\langle f\left(x_{t}\right)-y_{n}, J\left(x_{t}-y_{n}\right)\right\rangle=\left\langle f\left(x_{t}\right)-x_{t}, J\left(x_{t}-y_{n}\right)\right\rangle+\left\|x_{t}-y_{n}\right\|^{2} .
$$

Thus it follows from (3.3) that

$$
\begin{aligned}
\left\|x_{t}-y_{n}\right\|^{2} \leq & (1-t)^{2}\left(\left\|x_{t}-y_{n}\right\|+e_{n}\right)^{2} \\
& +2 t\left(\left\langle f\left(x_{t}\right)-x_{t}, J\left(x_{t}-y_{n}\right)\right\rangle+\left\|x_{t}-y_{n}\right\|^{2}\right) .
\end{aligned}
$$

Applying the Banach limit $\mu$ to (3.4), we have

$$
\begin{aligned}
\mu_{n}\left(\left\|x_{t}-y_{n}\right\|^{2}\right) \leq & (1-t)^{2} \mu_{n}\left(\left(\left\|x_{t}-y_{n}\right\|+e_{n}\right)^{2}\right) \\
& +2 t \mu_{n}\left(\left\langle f\left(x_{t}\right)-x_{t}, J\left(x_{t}-y_{n}\right)\right\rangle+\left\|x_{t}-y_{n}\right\|^{2}\right)
\end{aligned}
$$

and it follows from (3.5) that

$$
\mu_{n}\left(\left\langle x_{t}-f\left(x_{t}\right), J\left(x_{t}-y_{n}\right)\right\rangle\right) \leq t \mu_{n}\left(\left\|x_{t}-y_{n}\right\|^{2}\right) .
$$


From (3.2) and boundedness of $\left\{y_{n}\right\}$, it follows that

$$
t\left\|x_{t}-y_{n}\right\|^{2} \leq t\left(\frac{1}{1-k}\|f(z)-z\|+\left\|z-y_{n}\right\|\right)^{2} \rightarrow 0 \quad(\text { as } t \rightarrow 0) .
$$

Thus we conclude from Theorem J and (3.6) that

$$
\begin{aligned}
\mu_{n}\left(\left\langle(I-f)(Q(f)), J\left(Q(f)-y_{n}\right)\right\rangle\right) & \leq \limsup _{t \rightarrow 0} \mu_{n}\left(\left\langle x_{t}-f\left(x_{t}\right), J\left(x_{t}-y_{n}\right)\right\rangle\right) \\
& \leq 0 .
\end{aligned}
$$

Using Proposition 3.1 and the asymptotic regularity on the sequence $\left\{x_{n}\right\}$, we obtain the first main result.

Theorem 3.1. Let $E$ be a reflexive Banach space with a weakly sequentially continuous duality mapping $J$. Let $C$ be a nonempty closed convex subset of $E$ and $T$ nonexpansive mappings from $C$ into itself with $F(T) \neq \emptyset$. Let $\left\{\lambda_{n}\right\}$ and $\left\{\beta_{n}\right\}$ be sequences in $(0,1)$ which satisfies the conditions:

(C1) $\lim _{n \rightarrow \infty} \lambda_{n}=0 ; \sum_{n=0}^{\infty} \lambda_{n}=\infty$;

(C2) $\beta_{n} \in[0, a)$ for some $0<a<1$ for all $n \geq 0$.

Let $f \in \Sigma_{C}$ and $x_{0} \in C$ chosen arbitrarily. Let $\left\{x_{n}\right\}$ be the sequence generated by

$$
\left\{\begin{array}{l}
x_{0}=x \in C, \\
y_{n}=\lambda_{n} f\left(x_{n}\right)+\left(1-\lambda_{n}\right) T x_{n}, \\
x_{n+1}=\left(1-\beta_{n}\right) y_{n}+\beta_{n} T y_{n}, \quad n \geq 0 .
\end{array}\right.
$$

If $\left\{x_{n}\right\}$ is asymptotically regular, then $\left\{x_{n}\right\}$ converges strongly to $Q(f) \in F(T)$, where $Q(f)$ is the unique solution of the variational inequality

$$
\langle(I-f)(Q(f)), J(Q(f)-p)\rangle \leq 0, \quad f \in \Sigma_{C}, \quad p \in F(T) .
$$

Proof. We notice that by Theorem J, there exists a solution $Q(f)$ of a variational inequality

$$
\langle(I-f)(Q(f)), J(Q(f)-p)\rangle \leq 0, \quad f \in \Sigma_{C}, \quad p \in F(T) .
$$

Namely, $Q(f)=\lim _{t \rightarrow 0^{+}} x_{t}$, where $x_{t}$ is defined by $(\mathrm{R})$. We will show that $x_{n} \rightarrow Q(f)$.

We proceed with the following steps:

Step 1. $\left\|x_{n}-z\right\| \leq \max \left\{\left\|x_{0}-z\right\|, \frac{1}{1-k}\|f(z)-z\|\right\}$ for all $n \geq 0$ and all $z \in F(z)$ and so $\left\{x_{n}\right\},\left\{y_{n}\right\},\left\{f\left(x_{n}\right)\right\},\left\{T x_{n}\right\}$ and $\left\{T y_{n}\right\}$ are bounded.

Indeed, let $z \in F(T)$. Then we have

$$
\begin{aligned}
\left\|y_{n}-z\right\| & =\left\|\lambda_{n}\left(f\left(x_{n}\right)-z\right)+\left(1-\lambda_{n}\right)\left(T x_{n}-z\right)\right\| \\
& \leq \lambda_{n}\left\|f\left(x_{n}\right)-z\right\|+\left(1-\lambda_{n}\right)\left\|x_{n}-z\right\| \\
& \leq \lambda_{n}\left(\left\|f\left(x_{n}\right)-f(z)\right\|+\|f(z)-z\|\right)+\left(1-\lambda_{n}\right)\left\|x_{n}-z\right\| \\
& \leq \lambda_{n} k\left\|x_{n}-z\right\|+\lambda_{n}\|f(z)-z\|+\left(1-\lambda_{n}\right)\left\|x_{n}-z\right\| \\
& \left.=\left(1-(1-k) \lambda_{n}\right)\right)\left\|x_{n}-z\right\|+\lambda_{n}\|f(z)-z\|
\end{aligned}
$$




$$
\leq \max \left\{\left\|x_{n}-z\right\|, \frac{1}{1-k}\|f(z)-z\|\right\}
$$

and

$$
\begin{aligned}
\left\|x_{n+1}-z\right\| & =\left\|\left(1-\beta_{n}\right)\left(y_{n}-z\right)+\beta_{n}\left(T y_{n}-z\right)\right\| \\
& \leq\left(1-\beta_{n}\right)\left\|y_{n}-z\right\|+\beta_{n}\left\|y_{n}-z\right\| \\
& =\left\|y_{n}-z\right\| \leq \max \left\{\left\|x_{n}-z\right\|, \frac{1}{1-k}\|f(z)-z\|\right\} .
\end{aligned}
$$

Using an induction, we obtain

$$
\left\|x_{n}-z\right\| \leq \max \left\{\left\|x_{0}-z\right\|, \frac{1}{1-k}\|f(z)-z\|\right\}
$$

for all $n \geq 0$. Hence $\left\{x_{n}\right\}$ is bounded, and so are $\left\{y_{n}\right\},\left\{T x_{n}\right\},\left\{T y_{n}\right\}$ and $\left\{f\left(x_{n}\right)\right\}$. Moreover, it follows from condition (C1) that

$$
\left\|y_{n}-T x_{n}\right\|=\lambda_{n}\left\|f\left(x_{n}\right)-T x_{n}\right\| \rightarrow 0 \quad(\text { as } n \rightarrow \infty) .
$$

Step 2. $\lim _{n \rightarrow \infty}\left\|x_{n+1}-y_{n}\right\|=0$ and $\lim _{n \rightarrow \infty}\left\|x_{n}-y_{n}\right\|=0$. Indeed, by the condition (C2)

$$
\begin{aligned}
\left\|x_{n+1}-y_{n}\right\| & =\beta_{n}\left\|T y_{n}-y_{n}\right\| \\
& \leq \beta_{n}\left(\left\|T y_{n}-T x_{n} \mid+\right\| T x_{n}-y_{n} \|\right) \\
& \leq a\left(\left\|y_{n}-x_{n}\right\|+\left\|T x_{n}-y_{n}\right\|\right) \\
& \leq a\left(\left\|y_{n}-x_{n+1}\right\|+\left\|x_{n+1}-x_{n}\right\|+\left\|T x_{n}-y_{n}\right\|\right)
\end{aligned}
$$

which implies that

$$
\left\|x_{n+1}-y_{n}\right\| \leq \frac{a}{1-a}\left(\left\|x_{n+1}-x_{n}\right\|+\left\|T x_{n}-y_{n}\right\|\right) .
$$

So, by asymptotic regularity of $\left\{x_{n}\right\}$ and (3.7), we have $\left\|x_{n+1}-y_{n}\right\| \rightarrow 0$, and also

$$
\left\|x_{n}-y_{n}\right\| \leq\left\|x_{n}-x_{n+1}\right\|+\left\|x_{n+1}-y_{n}\right\| \rightarrow 0 \quad(\text { as } n \rightarrow \infty) .
$$

Step 3. $\lim _{n \rightarrow \infty}\left\|y_{n}-T y_{n}\right\|=0$ and $\lim _{n \rightarrow \infty}\left\|y_{n+1}-y_{n}\right\|=0$. By (3.7) and Step 2, we have

$$
\begin{aligned}
\left\|y_{n}-T y_{n}\right\| & \leq\left\|y_{n}-T x_{n}\right\|+\left\|T x_{n}-T y_{n}\right\| \\
& \leq\left\|y_{n}-T x_{n}\right\|+\left\|x_{n}-y_{n}\right\| \rightarrow 0 \quad(\text { as } n \rightarrow \infty) .
\end{aligned}
$$

Also asymptotic regularity of $\left\{x_{n}\right\}$ and (3.8) implies that

$$
\begin{aligned}
& \left\|y_{n+1}-y_{n}\right\| \\
\leq & \left\|y_{n+1}-x_{n+1}\right\|+\left\|x_{n+1}-x_{n}\right\|+\left\|x_{n}-y_{n}\right\| \rightarrow 0 \quad(\text { as } n \rightarrow \infty) .
\end{aligned}
$$

Step 4. $\lim \sup _{n \rightarrow \infty}\left\langle(I-f)(Q(f)), J\left(Q(f)-y_{n}\right)\right\rangle \leq 0$. To prove this, put

$$
a_{n}:=\left\langle(I-f)(Q(f)), J\left(Q(f)-y_{n}\right)\right\rangle, \quad n \geq 0 .
$$


Then, by $y_{n}-T y_{n} \rightarrow 0$ in Step 3, Proposition 3.1 implies that $\mu_{n}\left(a_{n}\right) \leq 0$ for any Banach limit $\mu$. Since $\left\{y_{n}\right\}$ is bounded, there exists a subsequence $\left\{y_{n_{j}}\right\}$ of $\left\{y_{n}\right\}$ such that

$$
\limsup _{n \rightarrow \infty}\left(a_{n+1}-a_{n}\right)=\lim _{j \rightarrow \infty}\left(a_{n_{j}+1}-a_{n_{j}}\right)
$$

and $y_{n_{j}} \rightarrow p$ for some $p \in E$. From $y_{n+1}-y_{n} \rightarrow 0$ in Step 3, it follows that $y_{n_{j}+1} \rightarrow p$. From the weak sequentially continuity of duality mapping $J$, we have

$$
w-\lim _{j \rightarrow \infty} J\left(Q(f)-y_{n_{j}+1}\right)=w-\lim _{j \rightarrow \infty}\left(J\left(Q(f)-y_{n_{j}}\right)=J(Q(f)-p),\right.
$$

and so

$$
\begin{aligned}
& \limsup _{n \rightarrow \infty}\left(a_{n+1}-a_{n}\right) \\
= & \lim _{j \rightarrow \infty}\left\langle(I-f)(Q(f)), J\left(Q(f)-y_{n_{j}+1}\right)-J\left(Q(f)-y_{n_{j}}\right)\right\rangle=0 .
\end{aligned}
$$

Then Lemma 2.3 implies that $\lim \sup _{n \rightarrow \infty} a_{n} \leq 0$, that is

$$
\limsup _{n \rightarrow \infty}\left\langle(I-f)(Q(f)), J\left(Q(f)-y_{n}\right)\right\rangle \leq 0 .
$$

Step 5. $\lim _{n \rightarrow \infty}\left\|x_{n}-Q(f)\right\|=0$. By using (IS), we have

$$
\begin{aligned}
\left\|x_{n+1}-Q(f)\right\| & \leq\left\|y_{n}-Q(f)\right\| \\
& =\left\|\lambda_{n}\left(f\left(x_{n}\right)-Q(f)\right)+\left(1-\lambda_{n}\right)\left(T x_{n}-Q(f)\right)\right\| .
\end{aligned}
$$

Applying Lemma 2.1, we obtain

$$
\begin{aligned}
& \left\|x_{n+1}-Q(f)\right\|^{2} \leq\left\|y_{n}-Q(f)\right\|^{2} \\
\leq & \left(1-\lambda_{n}\right)^{2}\left\|T x_{n}-Q(f)\right\|^{2}+2 \lambda_{n}\left\langle f\left(x_{n}\right)-Q(f), J\left(y_{n}-Q(f)\right)\right\rangle \\
\leq & \left(1-\lambda_{n}\right)^{2}\left\|x_{n}-Q(f)\right\|^{2}+2 \lambda_{n}\left\langle f\left(x_{n}\right)-f(Q(f)), J\left(y_{n}-Q(f)\right)\right\rangle \\
& +2 \lambda_{n}\left\langle f(Q(f))-Q(f), J\left(y_{n}-Q(f)\right)\right\rangle \\
\leq & \left(1-\lambda_{n}\right)^{2}\left\|x_{n}-Q(f)\right\|^{2}+2 k \lambda_{n}\left\|x_{n}-Q(f)\right\|\left\|y_{n}-Q(f)\right\| \\
& +2 \lambda_{n}\left\langle f(Q(f))-Q(f), J\left(y_{n}-Q(f)\right)\right\rangle \\
\leq & \left(1-\lambda_{n}\right)^{2}\left\|x_{n}-Q(f)\right\|^{2}+2 k \lambda_{n}\left\|x_{n}-Q(f)\right\|^{2} \\
& +2 k \lambda_{n}\left\|x_{n}-Q(f)\right\|\left\|y_{n}-x_{n}\right\| \\
& +2 \lambda_{n}\left\langle f(Q(f))-Q(f), J\left(y_{n}-Q(f)\right)\right\rangle .
\end{aligned}
$$

It then follows that

(3.9)

$$
\begin{aligned}
\left\|x_{n+1}-Q(f)\right\|^{2} \leq & \left(1-2(1-k) \lambda_{n}+\lambda_{n}^{2}\right)\left\|x_{n}-Q(f)\right\|^{2} \\
& +2 k \lambda_{n}\left\|x_{n}-Q(f)\right\|\left\|y_{n}-x_{n}\right\| \\
& +2 \lambda_{n}\left\langle f(Q(f))-Q(f), J\left(y_{n}-Q(f)\right)\right\rangle \\
\leq & \left(1-2(1-k) \lambda_{n}\right)\left\|x_{n}-Q(f)\right\|^{2}+\lambda_{n}^{2} M^{2}+2 \lambda_{n} k M\left\|y_{n}-x_{n}\right\| \\
& +2 \lambda_{n}\left\langle(I-f)(Q(f)), J\left(Q(f)-y_{n}\right)\right\rangle,
\end{aligned}
$$


where $M=\sup _{n \geq 0}\left\|x_{n}-Q(f)\right\|$. Put

$$
\begin{aligned}
\alpha_{n} & =2(1-k) \lambda_{n}, \\
\gamma_{n} & =\frac{\lambda_{n}}{2(1-k)} M^{2}+\frac{k M}{1-k}\left\|y_{n}-x_{n}\right\|+\frac{1}{1-k}\left\langle(I-f)(Q(f)), J\left(Q(f)-y_{n}\right)\right\rangle .
\end{aligned}
$$

From the condition (C1), Step 2 and Step 4 , it follows that $\alpha_{n} \rightarrow 0, \sum_{n=0}^{\infty} \alpha_{n}=$ $\infty$, and $\lim \sup _{n \rightarrow \infty} \gamma_{n} \leq 0$. Since (3.9) reduces to

$$
\left\|x_{n+1}-Q(f)\right\|^{2} \leq\left(1-\alpha_{n}\right)\left\|x_{n}-Q(f)\right\|^{2}+\alpha_{n} \gamma_{n},
$$

from Lemma 2.1 with $\delta_{n}=0$, we conclude that $\lim _{n \rightarrow \infty}\left\|x_{n}-Q(f)\right\|=0$. This completes the proof.

Remark 3.2. If $\left\{\lambda_{n}\right\}$ and $\left\{\beta_{n}\right\}$ in Theorem 3.1 satisfy conditions

(C1) $\lim _{n \rightarrow \infty} \lambda_{n}=0 ; \sum_{n=0}^{\infty} \lambda_{n}=\infty$;

(C2) $\beta_{n} \in[0, a)$ for some $0<a<1$ for all $n \geq 0$;

(C3) $\sum_{n=0}^{\infty}\left|\lambda_{n+1}-\lambda_{n}\right|<\infty ; \sum_{n=0}^{\infty}\left|\beta_{n+1}-\beta_{n}\right|<\infty$; or

(C4) $\lim _{n \rightarrow \infty} \frac{\lambda_{n}}{\lambda_{n+1}}=1 ; \quad \sum_{n=0}^{\infty}\left|\beta_{n+1}-\beta_{n}\right|<\infty$; or

(C5) $\left|\lambda_{n+1}-\lambda_{n}\right| \leq o\left(\lambda_{n+1}\right)+\sigma_{n}, \quad \sum_{n=0}^{\infty} \sigma_{n}<\infty$ (the perturbed control condition); $\quad \sum_{n=0}^{\infty}\left|\beta_{n+1}-\beta_{n}\right|<\infty$,

then the sequence $\left\{x_{n}\right\}$ generated by (IS) is asymptotically regular. Now we only give the proof in case when $\left\{\lambda_{n}\right\}$ and $\left\{\beta_{n}\right\}$ satisfy the conditions (C1), (C2) and (C5). Indeed, From (IS), we have for every $n \geq 1$,

$$
\left\{\begin{array}{l}
y_{n}=\lambda_{n} f\left(x_{n}\right)+\left(1-\lambda_{n}\right) T x_{n} \\
y_{n-1}=\lambda_{n-1} f\left(x_{n-1}\right)+\left(1-\lambda_{n-1}\right) T x_{n-1},
\end{array}\right.
$$

and so, for every $n \geq 1$, we have

$$
\begin{aligned}
& \left\|y_{n}-y_{n-1}\right\| \\
= & \|\left(1-\lambda_{n}\right)\left(T x_{n}-T x_{n-1}\right)+\lambda_{n}\left(f\left(x_{n}\right)-f\left(x_{n-1}\right)\right. \\
& \quad+\left(\lambda_{n}-\lambda_{n-1}\right)\left(f\left(x_{n-1}\right)-T x_{n-1}\right) \| \\
\leq & \left(1-\lambda_{n}\right)\left\|x_{n}-x_{n-1}\right\|+L\left|\lambda_{n}-\lambda_{n-1}\right|+k \lambda_{n}\left\|x_{n}-x_{n-1}\right\| \\
= & \left(1-(1-k) \lambda_{n}\right)\left\|x_{n}-x_{n-1}\right\|+L\left|\lambda_{n}-\lambda_{n-1}\right|,
\end{aligned}
$$

where $L=\sup \left\{\left\|f\left(x_{n}\right)-T x_{n}\right\|: n \geq 0\right\}$.

On the other hand, by (IS), we also have for every $n \geq 1$,

$$
\left\{\begin{array}{l}
x_{n+1}=\left(1-\beta_{n}\right) y_{n}+\beta_{n} T y_{n} \\
x_{n}=\left(1-\beta_{n-1}\right) y_{n-1}+\beta_{n-1} T y_{n-1} .
\end{array}\right.
$$

Simple calculations show that

$$
\begin{aligned}
x_{n+1}-x_{n}= & \left(1-\beta_{n}\right)\left(y_{n}-y_{n-1}\right)+\beta_{n}\left(T y_{n}-T y_{n-1}\right) \\
& +\left(\beta_{n}-\beta_{n-1}\right)\left(T y_{n-1}-y_{n-1}\right) .
\end{aligned}
$$


Then it follows that

$$
\begin{gathered}
\left\|x_{n+1}-x_{n}\right\| \leq\left(1-\beta_{n}\right)\left\|y_{n}-y_{n-1}\right\|+\beta_{n}\left\|y_{n}-y_{n-1}\right\| \\
+\left|\beta_{n}-\beta_{n-1}\right|\left\|T y_{n-1}-y_{n-1}\right\| .
\end{gathered}
$$

Substituting (3.10) into (3.11) and using the condition (C5), we derive

$$
\begin{aligned}
\left\|x_{n+1}-x_{n}\right\| \leq & \left(1-(1-k) \lambda_{n}\right)\left\|x_{n}-x_{n-1}\right\| \\
& +L\left|\lambda_{n}-\lambda_{n-1}\right|+M\left|\beta_{n}-\beta_{n-1}\right| \\
\leq & \left(1-(1-k) \lambda_{n}\right)\left\|x_{n}-x_{n-1}\right\| \\
& +L\left(o\left(\lambda_{n}\right)+\sigma_{n-1}\right)+M\left|\beta_{n}-\beta_{n-1}\right|,
\end{aligned}
$$

where $M=\sup \left\{\left\|T y_{n}-y_{n}\right\|: n \geq 0\right\}$. By taking $s_{n+1}=\left\|x_{n+1}-x_{n}\right\|$, $\alpha_{n}=(1-k) \lambda_{n}, \alpha_{n} \gamma_{n}=L o\left(\lambda_{n}\right)$ and $\delta_{n}=L \sigma_{n-1}+M\left|\beta_{n}-\beta_{n-1}\right|$ in (3.12), we have

$$
s_{n+1} \leq\left(1-\alpha_{n}\right) s_{n}+\alpha_{n} \gamma_{n}+\delta_{n}
$$

Hence, by the conditions (C1), (C5) and Lemma 2.2, $\lim _{n \rightarrow \infty}\left\|x_{n+1}-x_{n}\right\|=0$. Moreover, from (3.10) and the condition (C5), it follows that $\lim _{n \rightarrow \infty} \| y_{n}-$ $y_{n-1} \|=0$.

From this fact, we have the following:

Corollary 3.1. Let $E, C$ and $T$ be the same as in Theorem 3.1. Let $\left\{\lambda_{n}\right\}$ and $\left\{\beta_{n}\right\}$ be sequences in $(0,1)$ which satisfies the conditions $(\mathrm{C} 1),(\mathrm{C} 2)$ and $(\mathrm{C} 5)$ (or the conditions $(\mathrm{C} 1),(\mathrm{C} 2)$ and $(\mathrm{C} 3)$, or the conditions $(\mathrm{C} 1),(\mathrm{C} 2)$ and $(\mathrm{C} 4)$ ), $f \in \Sigma_{C}$ and $x_{0} \in C$ chosen arbitrarily. Let $\left\{x_{n}\right\}$ be the sequence generated by

$$
\left\{\begin{array}{l}
x_{0}=x \in C, \\
y_{n}=\lambda_{n} f\left(x_{n}\right)+\left(1-\lambda_{n}\right) T x_{n}, \\
x_{n+1}=\left(1-\beta_{n}\right) y_{n}+\beta_{n} T y_{n}, \quad n \geq 0 .
\end{array}\right.
$$

Then $\left\{x_{n}\right\}$ converges strongly to $Q(f) \in F(T)$, where $Q(f)$ is the unique solution of the variational inequality

$$
\langle(I-f)(Q(f)), J(Q(f)-p)\rangle \leq 0, \quad f \in \Sigma_{C}, \quad p \in F(T) .
$$

Remark 3.3. (1) Theorem 3.1 and Corollary 3.1 improve and complement the corresponding results in Moudafi [14] and $\mathrm{Xu}[22]$.

(2) Even $\beta_{n}=0$ in (IS), Corollary 3.1 generalizes the corresponding results in Halpern [6], Lions [12], Reich [17, 18], Shioji and Takahashi [19], Wittmann [20] and $\mathrm{Xu}[21]$ to the viscosity methods along with the perturb control condition (C5).

Next, we consider the viscosity approximation method with a weakly contractive mapping for the nonexpansive mapping.

Theorem 3.2. Let $E$ be a reflexive Banach space with a weakly sequentially continuous duality mapping $J$. Let $C$ be a nonempty closed convex subset of $E$ and $T$ nonexpansive mappings from $C$ into itself with $F(T) \neq \emptyset$. Let $\left\{\lambda_{n}\right\}$ 
and $\left\{\beta_{n}\right\}$ be sequences in $(0,1)$ which satisfies the conditions $(\mathrm{C} 1),(\mathrm{C} 2)$ and (C5) (or the conditions $(\mathrm{C} 1),(\mathrm{C} 2)$ and $(\mathrm{C} 3)$, or the conditions $(\mathrm{C} 1),(\mathrm{C} 2)$ and (C4)). Let $A: C \rightarrow C$ be a weakly contractive mapping and $x_{0} \in C$ chosen arbitrarily. Let $\left\{x_{n}\right\}$ be the sequence generated by

$$
\left\{\begin{array}{l}
x_{0}=x \in C \\
y_{n}=\lambda_{n} A x_{n}+\left(1-\lambda_{n}\right) T x_{n} \\
x_{n+1}=\left(1-\beta_{n}\right) y_{n}+\beta_{n} T y_{n}, \quad n \geq 0 .
\end{array}\right.
$$

Then $\left\{x_{n}\right\}$ converges strongly to $Q\left(A x^{*}\right)=x^{*} \in F(T)$, where $Q$ is a sunny nonexpansive retraction from $C$ onto $F(T)$.

Proof. It follows from Remark 3.1 that $F(T)$ is the sunny nonexpansive retract of $C$. Denote by $Q$ the sunny nonexpansive retraction of $C$ onto $F$. Then $Q \circ A$ is a weakly contractive mapping of $C$ into itself. Indeed,

$$
\|Q(A x)-Q(A y)\| \leq\|A x-A y\| \leq\|x-y\|-\psi(\|x-y\|) \text { for all } x, y \in C .
$$

Lemma 2.4 assures that there exists a unique element $x^{*} \in C$ such that $x^{*}=$ $Q\left(A x^{*}\right)$. Such a $x^{*} \in C$ is an element of $F(T)$.

Now we define a iterative scheme as follows:

$$
\left\{\begin{array}{l}
z_{n}=\lambda_{n} A x^{*}+\left(1-\lambda_{n}\right) T w_{n} \\
w_{n+1}=\left(1-\beta_{n}\right) z_{n}+\beta_{n} T z_{n}, \quad n \geq 0 .
\end{array}\right.
$$

Let $\left\{w_{n}\right\}$ be the sequence generated by (3.13). Then Corollary 3.1 with $f=$ $A x^{*}$ a constant assures that $\left\{w_{n}\right\}$ converges strongly to $Q\left(A x^{*}\right)=x^{*}$ as $n \rightarrow$ $\infty$. For any $n$, we have

$$
\begin{aligned}
& \left\|x_{n+1}-w_{n+1}\right\| \\
\leq & \left(1-\beta_{n}\right)\left\|y_{n}-z_{n}\right\|+\beta_{n}\left\|T y_{n}-T z_{n}\right\| \\
\leq & \left\|y_{n}-z_{n}\right\| \\
\leq & \lambda_{n}\left\|A x_{n}-A x^{*}\right\|+\left(1-\lambda_{n}\right)\left\|T x_{n}-T w_{n}\right\| \\
\leq & \lambda_{n}\left(\left\|A x_{n}-A w_{n}\right\|+\left\|A w_{n}-A x^{*}\right\|\right)+\left(1-\lambda_{n}\right)\left\|x_{n}-w_{n}\right\| \\
\leq & \left\|x_{n}-y_{n}\right\|-\lambda_{n} \psi\left(\left\|x_{n}-w_{n}\right\|\right)+\lambda_{n}\left(\left\|w_{n}-x^{*}\right\|-\psi\left(\left\|w_{n}-x^{*}\right\|\right)\right) \\
\leq & \left\|x_{n}-w_{n}\right\|-\lambda_{n} \psi\left(\left\|x_{n}-w_{n}\right\|\right)+\lambda_{n}\left\|w_{n}-x^{*}\right\| .
\end{aligned}
$$

Thus, we obtain for $s_{n}=\left\|x_{n}-w_{n}\right\|$ the following recursive inequality:

$$
s_{n+1} \leq s_{n}-\lambda_{n} \psi\left(s_{n}\right)+\lambda_{n}\left\|w_{n}-x^{*}\right\| .
$$

Since $\left\|w_{n}-x^{*}\right\| \rightarrow 0$, it follows from Lemma 2.5 that $\lim _{n \rightarrow \infty}\left\|x_{n}-w_{n}\right\|=0$. Hence

$$
\lim _{n \rightarrow \infty}\left\|x_{n}-x^{*}\right\| \leq \lim _{n \rightarrow \infty}\left(\left\|x_{n}-w_{n}\right\|+\left\|w_{n}-x^{*}\right\|\right)=0 .
$$

This completes the proof. 
Remark 3.4. Theorem 3.2 (and Corollary 3.3) develops and complements the corresponding results in Cho et al. [3], Halpern [6], Lions [12], Moudafi [14], Reich [17, 18], Shioji and Takahashi [19], Wittmann [20] and Xu [21, 22].

\section{References}

[1] Ya. I. Alber and A. N. Iusem, Extension of subgradient techniques for nonsmooth optimization in Banach spaces, Set-Valued Anal. 9 (2001), no. 4, 315-335.

[2] Ya. I. Alber, S. Reich, and J. C. Yao, Iterative methods for solving fixed-point problems with nonself-mappings in Banach spaces, Abstr. Appl. Anal. 2003 (2003), no. 4, 193216.

[3] Y. J. Cho, S. M. Kang, and H. Y. Zhou, Some control conditions on iterative methods, Comm. Appl. Nonlinear Anal. 12 (2005), no. 2, 27-34.

[4] I. Cioranescu, Geometry of Banach Spaces, Duality Mappings and Nonlinear Problems, Kluwer Academic Publishers, Dordrecht, 1990.

[5] K. Goebel and S. Reich, Uniform Convexity, Hyperbolic Geometry and Nonexpansive Mappings, Marcel Dekker, New York and Basel, 1984.

[6] B. Halpern, Fixed points of nonexpanding maps, Bull. Amer. Math. Soc. 73 (1967), 957-961.

[7] J. S. Jung, Iterative approaches to common fixed points of nonexpansive mappings in Banach spaces, J. Math. Anal. Appl. 302 (2005), no. 2, 509-520.

[8] Convergence theorems of iterative algorithms for a family of finite nonexpansive mappings, Taiwanese J. Math. 11 (2007), no. 3, 883-902.

[9] J. S. Jung and C. Morales, The Mann process for perturbed $m$-accretive operators in Banach spaces, Nonlinear Anal. 46 (2001), no. 2, Ser. A: Theory Methods, 231-243.

[10] J. S. Jung and D. R. Sahu, Convergence of approximating paths to solutions of variational inequalities involving non-Lipschitzian mappings, J. Korean Math. Soc. 45 (2009), no. 2, 377-392.

[11] T. H. Kim and H. K Xu, Strong convergence of modified Mann iterations, Nonlinear Anal. 61 (2005), no. 1-2, 51-60.

[12] P. L. Lions, Approximation de points fixes de contractions, C. R. Acad. Sci. Paris Ser. A-B 284 (1977), no. 21, A1357-A1359.

[13] L. S. Liu, Ishikawa and Mann iterative process with errors for nonlinear strongly accretive mappings in Banach spaces, J. Math. Anal. Appl. 194 (1995), no. 1, 114-125.

[14] A. Moudafi, Viscosity approximation methods for fixed-points problems, J. Math. Anal. Appl. 241 (2000), no. 1, 46-55.

[15] J. G. O'Hara, P. Pillay, and H. K. Xu, Iterative approaches to convex feasibility problems in Banach spaces, Nonlinear Anal. 64 (2006), no. 9, 2022-2042.

[16] B. E. Rhodes, Some theorems on weakly contractive maps, Nonlinear Anal. 47 (2001), no. 4, 2683-2693

[17] S. Reich, Strong convergence theorems for resolvents of accretive operators in Banach spaces, J. Math. Anal. Appl. 75 (1980), no. 1, 287-292.

[18] _ Approximating fixed points of nonexpansive mappings, Panamer. Math. J. 4 (1994), no. 2, 23-28.

[19] N. Shioji and W. Takahashi, Strong convergence of approximated sequences for nonexpansive mappings in Banach spaces, Proc. Amer. Math. Soc. 125 (1997), no. 12, 3641-3645.

[20] R. Wittmann, Approximation of fixed points of nonexpansive mappings, Arch. Math. (Basel) 58 (1992), no. 5, 486-491.

[21] H. K. Xu, Iterative algorithms for nonlinear operators, J. London Math. Soc. (2) 66 (2002), no. 1, 240-256. 
[22] _ Viscosity approximation methods for nonexpansive mappings, J. Math. Anal. Appl. 298 (2004), no. 1, 279-291.

[23] _ Strong convergence of an iterative method for nonexpansive and accretive operators, J. Math. Anal. Appl. 314 (2006), no. 2, 631-643.

Department of Mathematics

Dong-A University

BUSAN 604-714, Korea

E-mail address: jungjs@mail.donga.ac.kr 